\title{
Characteristics of Virgin Coconut Oil Emulsion with Honey and Citric Acid
}

\author{
Lastri Wiyani $^{1, *}$, Andi Aladin ${ }^{1}$, Mustafiah $^{1}$, Andi Abriana ${ }^{2}$, Rahmawati $^{3}$ \\ ${ }^{I}$ Departement of Chemical Engineering, Faculty of Industrial Technology-UMI, Makassar, Indonesia \\ ${ }^{2}$ Department of Food Technology, Faculty of Agricultural-Bosowa University, Makassar, Indonesia \\ ${ }^{3}$ Departement of Pharmacy Science, Faculty of Pharmacy-UMI, Makassar, Indonesia \\ "Corresponding author. Email: lastri.wiyani@umi.ac.id
}

\begin{abstract}
The present research was conducted aiming to examine the physical and chemical properties along with the stability of the emulsion of Virgin Coconut Oil (VCO) as an alternative product to decrease the oily taste when consuming the oil directly. The VCO emulsion involved in this research contains honey and citric acid with the ratio prepared of VCO : water : honey : is $80: 18: 2$. Furthermore, the combination of emulsifiers of Tween 80 and Span 80 was also used at the ratio of $2: 3$, particularly at $0.75 \%$ concentration, while the citric acid was prepared in various amount including $0.02,0.04,0.06,0.08$ and 0.1 gram in every $100 \mathrm{ml}$ emulsion. As a range of citric acid was provided in the research, it was found that as the citric acid amount increased, the viscosity and $\mathrm{pH}$ of emulsions decreased. Stable emulsion was obtained at citric acid amount of 0.02 to $0.06 \mathrm{gr} / 100 \mathrm{ml}$ emulsion. As much as 2.6 to $2.9 \mathrm{meq} / \mathrm{kg}$ sample of peroxide and 0.07 to $0.09 \%$ fatty acid were obtained, indicating that the emulsion produced was not rancid. Meanwhile, regarding the laurat acid contained, the amount contained was $49.22 \%$ which is still suitable as APCC standard for VCO.
\end{abstract}

Keywords: VCO emulsion, honey, citric acid, Tween 80, Span 80

\section{INTRODUCTION}

Virgin coconut oil (VCO) has been proven as a very useful product in health science aspect as it can be used for food supplements and cosmetic products' active compound. It its production, no heating processing was involved aiming to keep its properties. Instead, mechanical and natural technique was utilized to produce this alternative product made from fresh and mature coconuts [1] [2]. Recently, novel VCO form has been produced in order to make it more palatable and stable so that it can decrease the oily taste of VCO. Such form is formulated into VCO in the form of emulsion which also provides benefit in for the VCO-producing industry [3].

As emulsion has been utilized numerously as basic ingredients for many types of food product, its quality is essential to be considered. The quality of emulsion can be assessed through its stability in keeping its properties in order to not change over time, which means that the more stable the emulsion, means that the more difficult it is to change in terms of its properties over the time. Since emulsion is basically an unstable system in the context of its thermodynamics, it becomes a challenge for the industry to produce stable emulsion. The physicochemical characteristics of gums added during the aqueous stage of the emulsion is considered to be the ones affecting the emulsion stability [3], [4]. Thus, it was found that in order to achieve stability of emulsion, an addition of hydrocolloids during the aqueous stage is needed since it produces particular rheological properties. Hidrocolloids can act as surface active gums since it has the ability to create film in the oil droplets surrounding, making the coalescence takes slowly and prevent the emulsion to breakdown. In addition, some other hydrocolloids can stabilize the emulsion by increasing the viscosity of the aqueous stage [5] and [6].

There are various factor causing the breaking of emulsion's physical properties, including flocculation, gravitational, coalescence, separation, creaming and phase inversion. In addition, free radical mechanism caused by oil droplet aggregation in lipid oxidation can also decrease the stability of emulsion's physical nature [7]. However, kinetically stable (metastable) of emulsion is possible to be produced if their destabilization rate is adequately low in comparison with the expended lifespan [8], although it is thermodynamically unstable, by the additional of thickening agent or emulsifier before the homogenization [9]. Such addition will increase the system's activiation energy [10].

Numerous research regarding the use of emulsifiers on emulsion has been conducted. A research project [11] was conducted to stabilize sunflower oil emulsion by using various Bambara groundnut flour and starch as the stabilizer. Other stabilizer used in emulsion research are gum arabic [12], lecithin, xanthan gum [13], glycerin fatty ester acid [14], gum Odina [15], roselle extract [16]. Another research project [17] utilized the combination o Tween 80 and Span 80 as well as lecithin as emulsifiers in VCO emulsions stability [18]. The emulsion produced in 
the study had no taste. The addition of sweeteners and acids is necessary to produce a palatable emulsion. Beside that, the addition acid is very high can unstable emulsions. "Emulsion stability" in this research refers to the ability to keep its chemical and physical properties to stay unchanged over the time. Beverage emulsions physical stability determines its quality to be accepted by consumers. In addition, the long term stability of the emulsion depends on the rate and extent of changes occurs in its structure and properties.

The present study aims to investigate the effect of citric acid on the physical, chemical properties and stability of VCO emulsion containing honey. The expectation of this research is that by obtaining the insight regarding those effects, more stable and palatable VCO emulsion can be produced so that it can be implemented in VCO home industries.

\section{METHODS}

This research was performed at the Chemistry Laboratory of the Faculty of Industrial Technology and the Pharmacetics Laboratory of the Faculty of Pharmacy UMI, Makassar.

\section{a. Materials and equipment}

Virgin coconut oil (VCO) which is the basic material of this research was produced by CV. Avcol, Makassar, Indonesia. Meanwhile, the other materials including Low and high HLB surfactant, sorbitan monooleate (Span 80, HLB $=4.3$ ), polyoxyethylene sorbitan monooleate (Tween $80, \mathrm{HLB}=15.0$ ), honey and citric acid (food grade) were supplied by local chemical supplier.

UltraTurrax T25 IKA homogenizer was used to prepare the emulsions with the specification of $3600 \mathrm{rpm}$ as the minimum speed and $24000 \mathrm{rpm}$ as the maximum speedwith particle size of 1-10 micron. Furthermore, Brookfield viscometer model DV-I Prime was used to determine the viscosity.

This procedure was based on research conducted by Wiyani, [18], in which the VCO emulsion was provided with the ratio of VCO : water : honey $=80: 18: 2$ and $0.75 \%$ mixed of emulsifier T80S80 (2:3). Ultra Turrax homogenizer at $15,000 \mathrm{rpm}$ was then utilized to mix it for 4 minutes. Then, a range of citric acid amount was added $(0.02 \mathrm{~g}, 0.04 \mathrm{~g}, 0.06 \mathrm{~g}, 0.08 \mathrm{~g}$, and $0.1 \mathrm{~g})$ and stirred again using the same equipment for 1 minute [18].

\section{b. Evaluation}

\section{Peroxide Number Test}

A $300 \mathrm{~mL}$ Erlenmeyer flask was utilized to mix five grams of samples which was then added by $10 \mathrm{ml}$ of chloroform and $15 \mathrm{ml}$ of glacial acetic acid. Then, the mixture was also added by $1 \mathrm{ml}$ of saturated KI. The Erlenmeyer was immediately closed while shaken roughly for 5 minutes in the dark at a temperature of $15-25^{\circ} \mathrm{C}$. After that, $75 \mathrm{ml}$ of distilled water was also added and the Erlenmeyer was shaken vigorously. The solution of $0.2 \mathrm{~N}$ sodium thioslphate and starch solution was used as indicator to titrate the mic. The peroxide number was then showed in milieq /kg sample [19].

\section{Viscocity Test.}

Brookfield viscometer DV-I Prime was used to determine the emulsion that has been provided. Approximately $60 \mathrm{ml}$ of the emulsion was put in the erlenmeyer and tested for viscosity using a spindle 6 . The rotation speed was adjusted to $50 \mathrm{rpm}$ for 30 seconds. The device was then shows the value of the viscosity $(\mathrm{cP})$.

\section{Emulsion Stability Test.}

As much as $60 \mathrm{ml}$ of the sample was put into a bottle and stored in two stages. At the first stage it was stored at temperature of $5^{\circ} \mathrm{C}$ for 12 hours, while the second stage, it was stored at a temperature of $35^{\circ} \mathrm{C}$ for 12 hours. These stages were repeated for 10 times. The emulsion of VCO will be obtained through the following formula:

$\%$ stability $=$ (height of stable emulsion $/$ height of initial emulsion) $\mathrm{x} 100$ [20].

\section{Free Fatty Acid Test.}

An Erlenmeyer flask was used to mix 30 grams of sample, $50 \mathrm{ml}$ of hot neutral alcohol and $2 \mathrm{ml}$ of phenolphthalein (pp). As much as $0.1 \mathrm{~N} \mathrm{NaOH}$ was then use to titrate the mix in the Erlenmeyer flask until it turned pink and stay present for 30 seconds. The content of free fatty acid was shown in the form of \% FFA [19].

\section{RESULTS AND DISCUSSION}

The correlation between the citric acid provided and the viscosity of emulsion is presented in Figure 1. The concentration of citric acid increases in the prepared emulsion, the viscosity of system was lower until the addition of $0.1 \mathrm{~g} / 100 \mathrm{ml}$ of emulsion

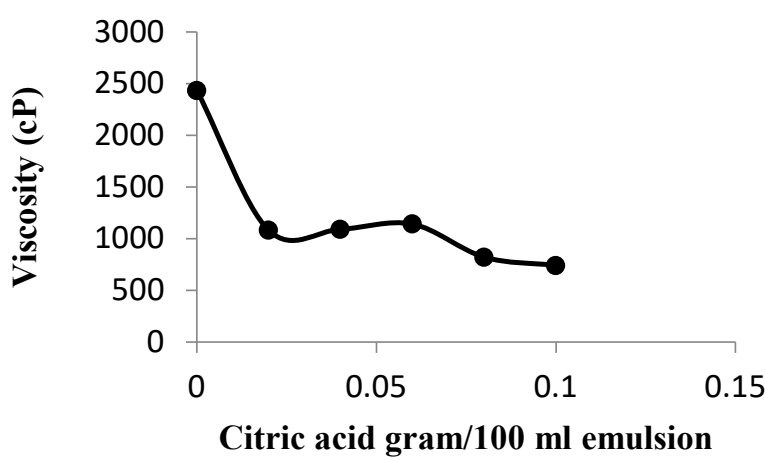

Figure 1. Relation beetwen the viscosity and the citric acid concentration of $\mathrm{VCO}$ emulsion

Based on the figure presented above, the emulsion's viscosity decreased as the citric acid amount decreased. However, the emulsion's viscosity can increase through the addition of sweeteners (glucose, sucrose, honey, etc.) since such addition can prevent the emulsion to become 
cream. However, if the viscosity was too high, it increased to form a creaming [21]. The high viscosity indicated the stability emulsion was good. However, if the viscosity value was too high, it could indicate that emulsion was broken. The emulsions became a flocculation because the structure of flocculation could trap the continuous phase (water) [22]. Other researchers explain, the addition of sugar or honey in the emulsion-shaped beverage can increase the continuous phase viscosity and prevent the occurrence of creaming. but the large viscosity difference between the dispersed and the continuous phases may also increase the rate of creaming [23].

Table 1. Characteristis of VCO emulsion at various concentration of citric acid

\begin{tabular}{|c|c|c|c|c|}
\hline $\begin{array}{c}\text { citric acid } \\
\mathbf{( g / 1 0 0 ~} \mathbf{~ m l} \\
\text { of } \\
\text { emulsion }\end{array}$ & Stability & $\mathbf{p H}$ & $\begin{array}{c}\text { Free } \\
\text { fatty } \\
\mathbf{a c i d} \\
\mathbf{( \% )}\end{array}$ & $\begin{array}{c}\text { Peroxide } \\
\text { Number } \\
\mathbf{( m e q} / \mathbf{k g})\end{array}$ \\
\hline 0 & Stable & 4.4 & 0.0952 & 3.0925 \\
0.02 & Stable & 4.3 & 0.0917 & 2.9802 \\
0.04 & Stable & 4.2 & 0.0763 & 2.7990 \\
0.06 & Stable & 4.1 & 0.0750 & 2.5874 \\
0.08 & Unstable & 3.9 & 0.0750 & 2.5946 \\
0.1 & Unstable & 3.7 & 0.0606 & 2.5822 \\
\hline
\end{tabular}

In order to be able to predict the shelf life of emulsion containing acidic or alkaline additive, producer needs to understand the insight regarding the effect of $\mathrm{pH}$ in food stability, pharmaceutical and industrial emulsions. The $\mathrm{pH}$ value of the VCO emulsion decreased as the concentration of citric acid increased as presented in Table 1. The VCO emulsion is stable at $\mathrm{pH} 4$. Generally, emulsion stability improves with increasing $\mathrm{pH}$ till neutrality, beyond which stability decreases. Thus, both acidity and alkalinity reduces the emulsion stability [11].

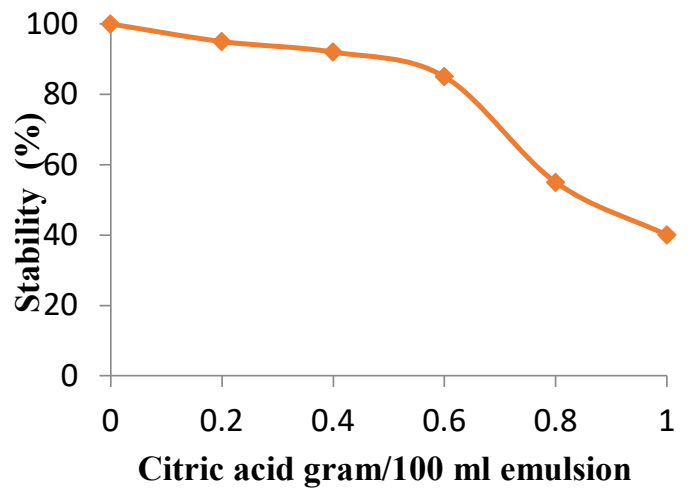

Figure 2. Stability of VCO emulsion

The emulsion stability is also influenced by the addition of citric acid (See Figure 2.) At 0.08-0.1g citric acid $/ 100 \mathrm{ml}$ emulsion resulted in an unstable emulsion. That phenomenons is influenced by components in honey.
There are some acids in honey, it called acetate, butyrate, formate, gluconate, lactate, maleate, oxalate, pyroglutamate, citrate, succinate, glycolate, aketoglutarate, pyruvate. The excessive addition of citric acid will affect the value of viscosity (decreased). A low viscosity will cause the droplets to easily move to the dispersing medium so that the droplets become very easily diffused. If the diffusion happen in droplets, there will be separation between dispersed substances and dispersing substances (separation of oil and water). This happens in VCO emulsion where the condition of acid are too high and will cause the emulsion to be damaged (unstable). Decrease in viscosity is followed by decreased stability of VCOE (Fig 1. and Fig. 2). The opportunity of fusion of the emulsion droplet is higher when it has low viscosity since it makes it easier to move in dispersion medium [24]. Such behavior occurs in the VCO emulsion containing vinegar [25] and VCO emulsion with sucrose and citric acid [26].

Based on the Table 1, it is known that the free fatty acids amount in the emulsion is quite low compared to the maximum free fatty acid content in VCO allowed by Asian and Pacific Coconut Community (APCC) standard, which is $0.5 \%$. Meanwhile, this research obtained that the free fatty acids contained in the emulsion is only at the range between $0.06 \%$ and $0.095 \%$. In addition, as a comparative content of free fatty acids, at coconut oil has a maximum of $5 \%$ free fatty acids [23]. The free fatty acids was produced for this research of VCO emulsion decreased as citric acid increased. The higher of the free fatty acids contain in the emulsion, the lower quality of the emulsion.

Table 2. Profile Fatty Acid of VCO emulsion with honey

\begin{tabular}{|l|c|c|}
\hline \multicolumn{1}{|c|}{ Content } & $\begin{array}{c}\text { VCO } \\
\text { Emulsion }\end{array}$ & $\begin{array}{c}\text { APCC VCO } \\
\text { standard [26] }\end{array}$ \\
\hline Caproic Acid (\%) & 0.41 & $0.10-0.95$ \\
Caprylic Acid (\%) & 6.44 & $4-10$ \\
\hline Capric Acid (\%) & 5.46 & $4-8$ \\
Lauric Acid (\%) & 49.22 & $43-53$ \\
\hline Miristic Acid (\%) & 18.37 & $16-21$ \\
Palmitic Acid (\%) & 9.72 & $7.5-10.2$ \\
\hline Linoleic Acid (\%) & 3.38 & $0.7-2.5$ \\
\hline
\end{tabular}

Peroxide compounds may be caused by industrial process treatment. The main damage of oil is due to oxidation and hydrolysis, both enzymatic and non-enzymatic. The results caused by fat oxidation include peroxide. In order to determine the damage level of oil is by determining the peroxide numbers. According to Table 1 presented, the peroxide numbers obtained based on the citric acid concentration provided was at the range between 2.58 and $3.09 \mathrm{milieq} / \mathrm{kg}$ sample. Such analysis was conducted aiming to know the amount of peroxide during the fats oxidation which can cause oil' rancidity. Based on the Codex-Stan 210-1999 the maximum level of peroxide number in virgin fat and oils is 15 milieq / $\mathrm{kg}$ sample. The maximum peroxide in VCO based on the APCC standard 
is 3 milieq / $\mathrm{kg}$ sample [27], which indicated that the emulsions were not rancid. Peroxide number in VCO is low because VCO contains approximately $90 \%$ of unsaturated fatty acids which are more resistant to rancidity due to oxidation process in comparison with unsaturated fatty acids [21].

The profile fatty acid of the VCO emulsion using Gas chromatography is presented in Table 3. The purpose of this analysis is to investigate the effect of the treatment on the profile fatty acid of VCOE. The main component of fatty acids in VCO is lauric acid. Laurat acid obtained was $49.22 \%$ (Table 3), which was in accordance with APCC standard for VCO, (43-53) \% [27].

\section{CONCLUSION}

Based on the research conducted, it can be known that as the citric acid amount provided is increased, the viscosity and $\mathrm{pH}$ of emulsions decreased. The concentration of citric acid which makes the emulsion stable is between 0.02-0.06 $\mathrm{gr} / 100 \mathrm{ml}$ emulsion. The amount of peroxide contained 2.6 to $2.9 \mathrm{meq} / \mathrm{kg}$ sample, while the free fatty acid content were 0.07 to $0.09 \%$, indicating that there was no rancidity in the emulsion. The amount of laurat acid obtained was $49.22 \%$, which was in at the range of APCC standard for VCO.

\section{ACKNOWLEDGMENT}

The authors would like to express gratitude to Ministry of Research Technology and Higher Education, the Republic of Indonesia for supporting this research.

\section{REFERENCES}

[1] Villarino, B. J., Dy B. J. and Lizada M. C. C. 2007. Descriptive sensory evaluation of virgin coconut oil and refined, bleached and deodorized coconut oil. LWT. Vol 40, p. 193-199.

[2] Aladin, A., Yani, S., Wiyani, L. Nurjannah dan Subaedah, S. 2016. Grated coconut waste as heating jacket and temperature stabiliser in the production of virgin coconut oil by natural fermentation. ARPN Journal of Engg. App. Scie. Vol. 11, No. 8.:5171-5176J. Clerk Maxwell, A Treatise on Electricity and Magnetism, 3rd ed., vol. 2. Oxford: Clarendon, 1892, pp.68-73.

[3] Rohman, A., Che Man, Y.B., Ismail, A. \& Hashim, P. 2010. Application of FTIR Spectroscopy for The Determination of Virgin Coconut Oil in Binary Mixtures with Olive Oil and Palm Oil. J. Am. Oil. Chem. Soc, 87, pp 601606.

[4] Nevin, K.G. \& Rajamohan, T., 2004. Beneficial Effects of Virgin Coconut Oil on Lipid Parameters and in Vitro LDL Oxidation. Clinical BioChemistry, 37, pp.830-835.
[5] Marina, A.M., Che Man, Y.B., Nazimah, S.A.H. \& Amin, I. 2009. Antioxidant Capacity and Phenolic Acids of Virgin Coconut Oil. Int. J. Food Sci. Nutr, 60, pp 114-123.

[6] Khor, Y. P., Koh, S. P., Long and K., Long, S. 2014. A Comparative Study of the Physicochemical Properties of a Virgin Coconut Oil Emulsion and Commercial Food Supplement Emulsions. mdpi.com M. Young, The Technical Writer's Handbook. Mill Valley, CA: University Science, 1989.

[7] Mosca, M., Cuomo F., Lopez, F. And Ceglie, A., 2013. Role of emulsifier layer, antioxidants and radical initiators in the oxidation of olive oil in water emulsions. Food Research International 50: 377-383

[8] Mirhosseni, H., Tan, C., Aghlara, A., Hamid, N., Yusof, S. \& Chern, B. 2008. Optimization of the contents of arabic gum, Xanthan gum and orange oil affecting turbidity, average particle size, polydispersity index and density in orange beverage emulsion. Food Hidrocolloid. 22: pp 1212-1223.

[9] McClements, D. J. 2004. Food Emulsions: Principles, Practice and Techniques. CRC Press, Florida.

[10] Meybodi, N.M., Mohammadifar, M.A., and Naseri, A,R. 2014. Effective factor on the stability of oil-in-water emulsion based beverage: A review. Journal of Food Quality and Hazard Control 1: 67-71

[11] Fasinu, E.G., Ikhu-Omoregbe, D.I. and Jideani, V.A. 2015. Influence of Selected Physicochemical Factors on The Stability of emulsions stabilized by Bambara groungnut Flour and Starch. J. Food Sci Technol 52 (11): 70487058 .

[12] Tensiska, Setiasih, I. S. \& Irawati, D. 2007. Description VCO (Virgin Coconut Oil) Emulsion Drink at Various Sum of Water Addition. (in Bahasa Indonesia). Proceedings of the Indonesian Association of Food Technologist Seminar, 17/18 July, Bandung, Indonesia.

[13] Traynor M. P., Burke R., Frias, J.M., Gaston, E. \& Barry-Ryan, C. 2013. Formation and Stability of an Oil in Water Emulsion Containing Lecithin, Xanthan Gum and Sunflower Oil. International Food Research Journal 20(5): 2173-2181.

[14] Bao Chengwei, An Shulin, Wang Wenli., Wang Fei, Y. Shuangchun \& Pan Yi. 2013. Research Progress in Glycerin Fatty Acid Ester Emulsifier. International Journal of Scientific \& Engineering Research. Volume 4:924-925. 
[15] Samanta, A., Ojha D., Mukherjee B., 2010. Stability Analysis of Primary Emulsion Using a New Emulsifying Agent Gun Odina. Journal Natural Science. Vol 2, No. 5: 495-505.

[16] Ibrahim N. H., Lee T. S., Rozaini M. Z. H. 2013. Potential Application of Rosella Extract in Functional Food Emusions. J. Tech and Food Industry. Vol 24, No. 1: 22-26.

[17] Wiyani, L., Aladin, A., Yani, S. \& Rahmawati. 2016a. Characteristics of Virgin Coconut Oil Emulsion Using Various of Emulsifiers. (in Bahasa Indonesia). PATPI, National Seminar Prosiding, August, 18-20, Makassar.

[18] Wiyani, L., Aladin, A., Yani, S. dan Rahmawati. 2016b. Stability of virgin coconut oil emulsion with mixed emulsifiers tween 80 and span 80 . ARPN Journal of Engg. App. Scie. Vol. 11, No. 8.: 5198-5202.

[19] Indonesian National Standard. 1994. How to Test Oils and Lipid. (in Bahasa Indonesia). (SNI 013555-1994). Jakarta, Indonesia.

[20] Tabibi dan Rhodes. 1996. Disperse Systems. In: Modern Pharmeceutics, Revised and Expanded. Banker G. S. and Rhodes C. R. (Eds.). CRC Press, USA.

[21] Fatimah, F., Rorong, J. \& Gugule, S., 2012. Stability and Viscosity of Oil-Honey Virgin Coconut Oil Emulsion Product. (in Bahasa Indonesia). Journal of Technology and Food Sciences, XXIII(1), pp.75-80.
[22] Hartayanie, L., Adriani, M. \& Lindayani. 2014. Characteristic of Coconut Milk and Soy Oil Emulsion with Added Gum Arab and Sucrose Ester. (in Bahasa Indonesia). Journal of Technology and Engineering Food, 2, 1979-7788.

[23] Taherian, AR., Fustier, P. Britten,M. \& Ramaswamy, HS. 2008. Rheology and Stability of Beverage Emulsions in The Presence and Absence of Weighthing Agents. A Review. Food Biophysics, 3, pp 279-286.

[24] Kailaku, SI., Hidayat, T. \& Setiabudy, DA. 2012. Effect of Homogenization Condition on Physical Characteristic and Quality of Coconut Milk During Storage Time. (in Bahasa Indonesia). Journal of Littri, 18, pp 31-39.

[25] Phaechamud, T. \& Katewongsa, P., 2010. Effect of Thermocycling on Stability of Emulsion Containing Virgin Coconut Oil and Hydrophobic Starch. Thesis. Silpakorn University, Thailand.

[26] Wiyani, L., Aladin, A., Yani, S., Mutmainnah S.H.N. and Mandang, H.D. 2018. Effect of Sucruse and citric acid addition in the Virgin Coconut Emulsion. IOP Conferences Series Vol 75:

[27] APCC. 2009. APCC Standards For Virgin Coconut Oil Asian and Pacific Coconut Community [cited: 05 July 2017. http://www.apccsec.org/document/VCO standard.pdf 